DOI:10.20396/cel.v60n3.8652230

(cc) $\overline{B Y}-\mathrm{NC}$

\title{
A BASE NACIONAL COMUM CURRICULAR BRASILEIRA E O LUGAR DA FONÉTICA E DA FONOLOGIA NO ENSINO FUNDAMENTAL ANOS INICIAIS ${ }^{1}$
}

\author{
SIANE GOIS CAVALCANTI RODRIGUES* \\ CRISTINA MANUELA SÁ**
}

\begin{abstract}
RESUMO: Apesar de serem áreas de fundamental importância à reflexão sobre a língua e à ampliação dos saberes linguísticos dos alunos, a Fonética e a Fonologia, tradicionalmente, fazem-se presentes no currículo escolar brasileiro de maneira incipiente (CAGLIARI, 2009). Nesse contexto, o objetivo desta pesquisa foi analisar o espaço ocupado por essas áreas na recém-lançada Base Nacional Comum Curricular (BRASIL, 2017), especificamente no Ensino Fundamental Anos Iniciais. O estudo fundamentou-se em Cagliari (2009) e em Simões (2006) e evidenciou que as áreas em pauta têm papel de destaque nesse nível de ensino durante todo o processo de apropriação e de sedimentação do sistema de escrita alfabética. Entretanto, mostrou também que, apesar de se embasar no sociointeracionismo discursivo para apresentar a sua compreensão de língua e de linguagem, a BNCC distancia-se de tal perpectiva, ao tratar a variação linguística como um conteúdo (um objeto do conhecimento) e não como um princípio que transversaliza a Fonética e a Fonologia, bem como os demais níveis de análise linguística, o que contribui com o fortalecimento da visão genérica e estereotipada do fenômeno.
\end{abstract}

Palavras-chave: fonética; fonologia; ensino de língua portuguesa.

ABSTRACT: Despite the fact that Phonetics and Phonology are areas of fundamental importance in the reflection on language and the broadening of students' linguistic knowledge, traditionally they are presented in the Brazilian school curriculum in a rudimentary fashion (CAGLIARI, 2009). In this context, the objective of this research was to analyze the space occupied by these areas in the recently released Brazilian National Curriculum Standard Base (BRASIL, 2017), specifically in reference to the Early Years of Elementary Education. The study is based on Cagliari (2009) and Simões (2006) who show that the areas in focus have a featured role at this level of teaching throughout the entire process of appropriation and sedimentation of the alphabetic writing system. However, it also shows that, despite being based on discursive sociointeractivism, with regard to the concept of language (as a whole) and the language (in use), the BNCC diverts from this perspective by treating linguistic variation as content (an object of knowledge) and not as a principle that permeates Phonetics and Phonology, as well as the other levels of linguistic analysis, thus contributing to strengthening the generic and stereotyped vision of the phenomenon.

Keywords: phonetics; phonology; portuguese language teaching.

${ }^{*}$ Universidade Federal de Pernambuco (UFPE), Recife, PE, Brasil. sianegois@yahoo.com.br

** Universidade de Aveiro, Aveiro, Portugal. cristina@ua.pt

${ }^{1}$ Esta investigação insere-se no contexto de uma pesquisa mais abrangente, que vem sendo desenvolvida pela autora em seu estágio de pós-doutorado, pela Universidade de Aveiro (Portugal), sob orientação da Professora Doutora Cristina Manuela Sá. 


\section{INTRODUÇÃO}

O caráter prescritivo dos currículos e as relações de poder que os envolvem fazem com que a sua implementação, especialmente em se tratando de um currículo em âmbito nacional, não aconteça consensualmente, porquanto demanda posicionamentos valorativos, axiológicos de sujeitos que participam de grupos distintos e ocupam, portanto, diferentes posições sociais.

A produção e a efetivação da BNCC foram permeadas por inúmeras discussões entre educadores, evidenciadas pelo número de consultas públicas feitas pelo Ministério da Educação. Mesmo assim, ainda há muitas críticas ao documento, em debates que acontecem em fóruns acadêmicos presenciais e virtuais.

A presente investigação materializa a nossa participação nesse debate, a partir de uma posição social específica: a de professora de Fonologia da Língua Portuguesa, que atua na formação de licenciandos em Letras de uma universidade pública federal. Considerando a importância da Fonética e da Fonologia à reflexão sobre a língua e à ampliação dos saberes linguísticos dos alunos da Educação Básica e levando em conta o fato de, tradicionalmente, essas áreas fazerem-se presentes no currículo escolar brasileiro de maneira incipiente (CAGLIARI, 2009), objetivamos prescrutar o lugar reservado, pela $\mathrm{BNCC}$, às supracitadas áreas.

Para tanto, realizou-se um estudo de natureza qualitativa, por meio de uma análise de cunho interpretativo, que possibilitou a descrição e a explicação minuciosa dos dados. O texto organiza-se da seguinte maneira: abordamos, na fundamentação teórica, a importância da Fonética e da Fonologia no ensino da Língua Portuguesa, em contraposição ao parco espaço que tais áreas, tradicionalmente, ocupam no currículo. A seguir, na análise dos dados, após a exposição da estrutura da BNCC, investigamos o lugar das áreas em pauta no Ensino Fundamental Anos Inicias para, então, tecermos as considerações finais.

\section{FUNDAMENTAÇÃO TEÓRICA}

\subsection{A Fonética e a Fonologia na Educação Básica Brasileira: Algumas Considerações Sumárias}

As práticas pedagógicas escolares relativas ao ensino de Língua Portuguesa refletem, de forma geral, a maneira como essa disciplina se constituiu ao longo da história do Brasil, como muito bem o demonstram os estudos no campo da historiografia do português brasileiro. De maneira específica, e considerado um recorte temporal menor, elas também resultam dos variados desdobramentos por que passou a Linguística moderna, desde a publicação, no ínicio do século passado, do Curso de Linguística Geral, de Ferdinand de Saussure (2006 [1916]). Especialmente nas últimas cinco décadas, ela desenvolveu-se muito rapidamente, o que pode ser evidenciado com o surgimento de campos de estudo que objetivavam contemplar o extraliguístico que fora deixado de lado pelo mestre genebrino no seu ato de fundação da Linguística moderna, tais como a sociolinguítica, a 
psicolinguística, a pragmática, as análises do discurso, as teorias da enunciação e a linguística de texto.

$\mathrm{O}$ processo de transposição didática que viabiliza a chegada desses desdobramentos às escolas demanda muitos anos, uma vez que ele não acontece sem que haja mudanças curriculares significativas nos cursos de Letras e investimento em políticas públicas de formação continuada docente. $\mathrm{O}$ caso do Brasil é bastante representativo dessa a realidade, uma vez que inúmeros docentes, ainda nos dias de hoje, são alheios a esse processo, seja porque a sua formação inicial não lhes deu os subsídios teórico-metodológicos necessários, seja porque eles não têm acesso a bons cursos de formação continuada. A esse respeito, Cagliari afirma o seguinte:

\footnotetext{
Na verdade, a evolução rápida e profunda por que passou a linguística moderna deixou muitos professores perplexos, não só diante do trabalho que vinham desenvolvendo ao longo dos muitos anos no próprio magistério, como também pelo fato de verem seus grandes mestres criticados, ou mesmo contestados, em questões fundamentais. (CAGLIARI, 2009, pp. 34-35)
}

Essa realidade tem diferentes consequências e o péssimo desempenho em escrita de milhares de candidatos que participam anualmente do Exame Nacional do Ensino Médio (ENEM) é uma delas. Eles não dominam, como deveriam, a ortografia de sua própria língua materna, porque, não conhecendo devidamente o princípio da escrita alfabética, tampouco a Fonética e a Fonologia do português, tendem a confundir os princípios da fala e da escrita e a produzir a chamada escrita oralizada. Esse desconhecimento é, por sua vez, consequência da má formação do professor, que também não construiu, em sua formação inicial, saberes imprescindíveis à sua práxis. Nesse ínterim, a escola mostra a sua ineficácia, o seu fracasso no cumprimento de sua missão mais básica.

Para ilustrar tal problema, tomemos como exemplo a pesquisa realizada por Rodrigues e Nascimento (2016), que contou com a participação de um grupo de 28 professores das redes públicas estadual e municipal de ensino de Pernambuco. As autoras tomaram como material de coleta de dados um questionário que foi respondido pelos voluntários, para observar o tratamento que os referidos docentes dispensavam a problemas de motivações fono-ortográficas verificados na produção escrita de alunos da Educação Básica nos mais diferentes níveis. A análise evidenciou que a grande maioria dos participantes não possuía conhecimentos basilares da Fonética e da Fonologia indispensáveis a uma intervenção pedagógica eficaz, que leve o aluno a refletir sobre a natureza do seu equívoco e, então, superálo. Tal problema contribui para a sedimentação de equívocos de escrita inaceitáveis no Ensino Fundamental Anos Finais e no Ensino Médio.

Parece óbvio, pois, que a Fonética e a Fonologia precisam ser dominadas pelos professores de português, sob pena de o raciocínio linguístico dos seus alunos, quando cometem determinados desvios de grafia, ser negligenciado pelo docente, o qual, nesse ínterim, não será capaz de construir as hipóteses teóricas que susterão a sua intervenção pedagógica. Segundo Simões (2006, p. 62): 
[...] muitas das dificuldades atribuídas, no processo de ensino-aprendizagem do vernáculo, à heterogeneidade e à falta de prontidão (biológica ou psicológica) do alunado nada mais são que resultantes de ações pedagógicas impróprias e, muitas vezes, decorrentes de uma carência técnico-teórica docente no que se refere ao domínio da estrutura e do funcionamento da língua materna. Não que o docente seja descomprometido com o processo, mas, por falha na sua formação, não se tenha habituado à pesquisa e à reflexão sobre os temas que, no curso de sua prática, venham a apresentar-se como problemáticos, carecendo, assim, de maior esclarecimento e de novos recursos táticos para explanção didática.

Ainda que não seja o objetivo deste trabalho discurtir acerca das potencialidades e dos problemas relativos ao caráter essencialmente discursivo das diferentes edições dos Parâmetros Curriculares Nacionais, fica, subjacente ao cenário sucintamente apresentado, a pergunta acerca do que deve ser, afinal, o objeto de ensino da disciplina Língua Portuguesa nas escolas. Não resta dúvidas de que o foco majoritariamente dado, nas escolas, ao trabalho com os gêneros textuais, verificado especialmente nos anos que sucederam a publicação da primeira edição dos Parâmetros Curriculares Nacionais, em 1997, não resolveu o problema do mau desempenho em leitura e em escrita dos nossos alunos ${ }^{2}$.

Também não cabe à escola, obviamente, a missão de formar alunos especialistas em Fonética e em Fonologia. Mas ela não pode, contudo, negar-lhes o direito de conhecer uma das dimensões de sua língua materna. Nesse sentido é que advogamos, como o faz Cagliari (2009), a favor da ampliação do espaço dessas duas áreas em todo o currículo da Educação Básica:

Os currículos escolares, principalmente os que o professor de fato executa nas salas de aula, fazem os estudos girar em torno, sobretudo, da morfologia e da sintaxe, e isso do ponto de vista da escrita e do dialeto-padrão. Falta um estudo profundo da fonética, fonologia, semântica, sociolinguística, de gramática e de análise do discurso. Parece incrível, mas é verdade: as pessoas estudam português durante tantos anos e não sabem como falam, quais os sons que realmente usam quando falam sua própria língua. (GAGLIARI, 2009, p. 42)

Como bem observa o autor, no currículo que, de fato, é vivido nas salas de aula, o ensino do aspecto estrutral contempla a Moforlogia e a Sintaxe, em detrimento da Fonética e da Fonologia ${ }^{3}$. É importante salientar que esse dado não diz respeito apenas à realidade brasileira. Isso está sendo constatado em uma pesquisa de pós-doutoramento que estamos realizando no Laboratório de Investigação em Educação em Português (LEIP) ${ }^{4}$, do Departamento de Educação e Psicologia da Universidade de Aveiro /Portugal, cujo objetivo é fazer um estudo comparativo

\footnotetext{
${ }^{2}$ Não estamos, com isso, afirmando que os Parâmentros Curriculares Nacionais desconsiderem o aspecto estrutural a língua. Tampouco desmerecendo a importância do ensino fundado na perspectiva teórica do socio-interacionismo discursivo, para o desenvolvimento de competências caras às vivências sociais dos alunos. A bandeira que ora levantamos diz respeito às consequências, para o ensino, de opções extremistas.

${ }^{3}$ Problema semelhante acontece com outros níveis de análise linguística, como a semântica e a pragmática, e as pesquisas que se voltam ao estudo dessa questão trazem resultados bastantes relevantes acerca do que realmente se ensina nas salas de aula da disciplina Língua Portuguesa, nas escolas da Educação Básica Brasileira.

${ }^{4}$ O LEIP é integrado ao Centro de Investigação Didática e Tecnologia na Formação de Formadores (CIDTFF)
} 
acerca do espaço reservado à Fonética e à Fonologia em livros didáticos de Língua Portuguesa e nas orientações curriculares nacionais de ambos os países. No que tange à realidade lusitana, os resultados indicam que o programa curricular em vigor determina metas curriculares, descritores de desempenho e conteúdos da Fonética e da Fonologia para os dois anos finais do $3^{\circ}$ ciclo ${ }^{5}$, mas não antevê, para os anos que antecedem o $8^{\circ}$ e o $9^{\circ}$, conteúdos necessários a tal abordagem. Isso significa que caberia ao professor criar mecanismos para preencher tal lacuna, de maneira a, em um mesmo ano, abordar saberes realtivos aos 4 anos de escolaridade $\left(4^{\circ}, 5^{\circ}, 6^{\circ}\right.$ e $\left.7^{\circ}\right)$ em que a Fonética e a Fonologia são postas de lado pelo programa, o que é, sem dúvidas, inviável.

Observe-se o que afirmam Veloso e Rodrigues (2006, p. 115), ao destacar a insuficiência, por parte de alunos do Ensino Básico e Secundário daquele país, de conhecimentos relativos às áreas em pauta, em comparação com os saberes construídos nos outros níveis de análise da língua:

[...] existe, de facto, um défice de conhecimento explícito das noções de fonética e fonologia na generalidade do $\mathrm{EBS}^{6}$. Com efeito, parece-me realista admitir que, de uma forma geral, qualquer aluno do final do $12^{\circ}$ ano ${ }^{7}$ de escolaridade saberá minimamente identificar e classificar categorias morfossintactas e sintactas ou ainda identificar processos flexionais da língua; porém dificilmente um aluno desse nível de escolaridade usará termos como "consoante fricativa", "vogal semifechada", "sílaba aberta", entre outros, no seu discurso explícito sobre as propriedades da sua língua. (VELOSO e RODRIGUES 2006, p. 115)

No caso do Brasil, tal carência é consequência do parco espaço que essas áreas, tradicionalmente, têm nas orientações curriculares nacionais. Se órgãos governamentais responsáveis pela criação e pela implementação do currículo não reconhecem a importância desses campos para a ampliação dos saberes linguísticos dos alunos e acabam por suprimir ou minimizar a sua presença nas orientações curriculares nacionais, elas, por sua vez, também não se farão presentes nos livros didáticos de Língua Portuguesa. Tais inquietações motivaram a análise que segue.

Cabe alertar o leitor acerca do fato de que não pretendemos abordar a questão do ponto de vista da Historiografia (o que, certamente, seria uma profícua maneira e analisar o fenômeno). Assim, as nossas considerações limitaram-se a um recorte temporal específico, a partir da análise da recente Base Nacional Comum Curricular (BRASIL, 2017), especificamente do segmento que trata do Ensino Fundamental Anos Iniciais. A escolha desse nível escolaridade e a opção por abordar a relação Fonética/Folongia e ensino de Língua Portuguesa justificouse na medida em que, considerando tudo o que já foi até aqui explanado, não resta dúvidas de que, à formação de leitores e escritores proficientes em sua língua materna, é imprescindível uma consolidada formação de base nos campos em pauta. Foi isso que procuramos mostrar nesta seção.

${ }^{5}$ Em Portugal, o terceiro ciclo corresponde ao $7^{\circ}, 8^{\circ}$ e $9^{\circ}$ ano do Ensino Fundamental Anos Finais do Brasil

${ }^{6}$ Ensino Básico eEnsino Secundário.

${ }^{7}$ Essa série, no Brasil, corresponde ao $3^{\circ}$ ano do Ensino Médio. 


\section{ANÁLISE DOS DADOS}

\subsection{A BNCC: Dimensão linguística dos saberes da Fonética e da Fonologia no Ensino Fundamental Anos Iniciais}

No mês de abril de 2013, o Ministério da Educação brasileiro iniciou o debate acerca da implementação de um novo currículo para a Educação Básica, sob a justificativa de atingir a tão sonhada equidade educacional e de eliminar as históricas desigualdades da sociedade brasileira. Em junho de 2014, foi prevista, pelo então aprovado Plano Nacional de Educação - PNE ${ }^{8}$ (BRASIL, 2014), a implantação da Base Nacional Comum Curricular (BNCC), o que deveria acontecer até o mês de junho de 2016.

No mês de junho de 2015, professores de 38 universidades, educadores e técnicos das secretarias estaduais formaram um grupo de trabalho, cujo objetivo era elaborar o documento. No mês seguinte, a Secretaria de Educação Básica lançou o portal BNCC, que objetivou propiciar a partipação popular nas discussões e manter a sociedade informada acerca da elaboração do texto, cuja primeira versão foi disponibilizada para consulta entre os meses de outubro de 2015 e março de 2016.

Segundo dados constantes do site do Ministério da Educação ${ }^{9}$, houve" [...] 12 milhões de contribuições - individuais, de organizações e de redes de educação de todo o país -, além de pareceres analíticos de especialistas, associações científicas e membros da comunidade acadêmica" (BRASIL, 2017, p. 5). Em maio de 2016, a segunda versão da BNCC foi publicada e "[...] passou por um processo de debate institucional em seminários realizados pelas Secretarias Estaduais de Educação em todas as Unidades da Federação" (BRASIL, 2017, p. 5) e, por fim, no ano de 2017, a terceria e última versão foi publicada.

A BNCC apresenta a seguinte estrutura: depois da apresentação, há a introdução, onde é possível conhecer os marcos legais, a natureza interfederativa, os fundamentos pedagógicos, bem como as competências gerais do documento. Após a apresentação do organograma da estrutura do documento, são definidos os níveis de ensino da Educação Básica. A seguir, expõe-se a sua ordenação por meio das 4 áreas do conhecimento: Linguagens (Língua Portuguesa, Arte, Educação Física e Língua Inglesa), Matemática, Ciências da Natureza e Ciências Humanas (Geografia e História).

Na seção em que se encontra a caracterização da área de Linguagens, observase que o conceito de linguagem, que é tomada como objeto de reflexão e análise e como um sistema semiótico (verbal, não-verbal e multimodal), é fundamentado no sociointeracionismo discursivo. Tal sistema

${ }^{8}$ O Plano Nacional de Educação é um documento no qual devem-se basear os planos municipais, estaduais e distritais. Nele estão delineadas 20 metas para a educação nacional, as quais se organizam em blocos que tratam do acesso, da universalização, da alfabetização e da ampliação da escolaridade e das oportunidades educacionais; da redução das desigualdades e da valorização da diversidade e, por fim, da valorização dos profissionais da educação.

${ }^{9}$ Disponível em http://basenacionalcomum.mec.gov.br/images/pdf/0_BNCC-Final_Apresentacao.pdf. Acesso em 03/08/2017. 
[...] pressupõe interação entre as pessoas que participam do ato comunicativo com e pela linguagem. Cada ato de linguagem não é uma criação em si, mas está inscrito em um sistema semiótico de sentidos múltiplos e, ao mesmo tempo, em um processo discursivo. (BRASIL, 2017, p. 59)

Nessa perspecitva, a linguagem é aquilo que possibilita a interação entre os sujeitos e os discursos, enquanto fenômeno essencialmente heterogêneo que, longe de encerrar-se em si mesmo, é constantemente ressignificado no complexo processo de produção discursiva. Ao estudo e à compreensão das práticas de linguagens, é imprescindível a análise da sua constituição histórica e contextual. Tais princípios, como não poderia deixar de ser, são subjacentes às 8 competências gerais delineadas pelo documento para a área de Linguagens, as quais preveem ações atitudinais, como o desenvolvimento da visão crítica, o confronto de opiniões e de pontos de vista, o respeito às diferentes linguagens e a interação por meio delas.

Após a caracterização da área de Linguagens, apresenta-se a concepção de língua, a qual vai estruturar a maneira como o documento concebe os objetos de ensino da disciplina de Língua Portuguesa, em seus cinco eixos organizadores. A língua é considerada em sua bimodalidade e, nesse sentido, o seu ensino deve pressupor o contínuo entre oralidade e escrita e o texto, considerado em sua multimodalidade, é "[...] o centro das práticas de linguagem e, portanto, o centro da BNCC para Língua Portuguesa" (BRASIL, 2017, p. 63).

Nessa perspectiva, o documento parte do reconhecimento do fato de que o aluno já chega à escola dominando uma certa dimensão da Oralidade de sua língua, que ele desenvolveu, em seu meio social, na interação com os outros. Nesse contexto, é explicitada a dimensão do oral ensinável na escola: aquela que o aluno normalmente não aprende fora do ambiente acadêmico. Prevê-se, portanto, o estudo das características da oralidade em comparação com a escrita, os usos que se adequam às diferentes situações de comunicação e o respeito à variação linguística.

Por sua vez, a Leitura é tomada como tema central e o seu ensino deve contemplar, dentre outros aspectos, o domínio do sistema alfabético de escrita, a interpretação e a compreensão de textos (verbais, verbo-visuais e multimodais) e a "identificação de gêneros textuais" 10 .

Para a Escrita, o documento determina o trabalho com a produção de textos (também verbais, verbo-visuais e multimodais) de diferentes gêneros e o desenvolvimento da habilidade de codificação de textos coerentes, coesos, adequados à situação de interação, do ponto de vista da informatividade e dos usos linguísticos.

A Educação Literária é um eixo considerado pela BNCC como muito próximo do eixo da Leitura, embora tenha objetivos distintos. Seu principal propósito não é

${ }^{10}$ Destacamos esse termo porque chamou a nossa atenção a sua natureza conteudista, instrucionista, o que vai de encontro à orientação teórica do documento no que diz respeito ao desenvolvimento de competências reflexivas e atitudinais em todos as disciplinas. Não nos prolongaremos, no entanto, nessa questão, porque ela foge aos objetivos desta pesquisa. 
o ensino da literatura em si, mas oportunizar a formação de leitores literários. Para tanto, a meta é colocar esses estudantes em contato com textos literários orais e escritos, produzidos em língua portuguesa, mas também com as traduções para o português de obras clássicas estrangeiras.

Por seu turno, o eixo Conhecimentos Linguísticos e Gramaticais engloba desde o processo de alfabetização, no Ensino Fundamental Anos Iniciais, às “[...] práticas de análise linguística e gramatical, estreitamente relacionadas com o desenvolvimento produtivo das práticas de oralidade, leitura e escrita" (BRASIL, 2017, p. 64), no Ensino Fundamental Anos Finais.

Observa-se, nessa caracterização introdutória dos 5 eixos de ensino, que o texto tem como base o sociointeracionismo discursivo, em conformidade com a configuração anteriormente feita da área de linguagens. Entretanto, a Fonologia e a Fonética não aparecem associadas ao supracitado desenvolvimento das práticas de oralidade, leitura e escrita, como se pode ver no segmento final do texto que introduz o eixo em pauta:

A reflexão sobre a estrutura linguística e as regras de concordância e de regência e a apropriação de recursos semânticos, sintáticos e morfológicos são fundamentais para a expansão da capacidade de produzir e de interpretar textos. Insere-se nesse eixo a aprendizagem das normas ortográficas e da pontuação, contextualizadas no desenvolvimento da leitura e da escrita. (BRASIL, 2017, p. 65).

Ao mesmo tempo em que a Sintaxe é mencionada duas vezes (na referência às regras de concordância e de regência e aos recursos sintáticos), a Fonologia, o primeiro nível de análise linguística, sequer é considerada no processo de reflexão sobre a língua de que trata o texto.

Após a explanação acerca dos 5 eixos organizadores - que se estruturam em unidades temáticas, objetos de conhecimento e habilidades -, o leitor é advertido de que tais habilidades respeitam uma progressão de nível de complexidade no decorrer do nível de ensino a que se destinam.

No segmento seguinte, são delineadas 10 competências específicas de Língua Portuguesa para o Ensino Fundamental. Em conformidade com os objetivos propostos nesta pesquisa, o nosso olhar voltou-se para os segmentos do texto em análise que guardam relação com as áreas em estudo. Assim, transcrevemos, abaixo, dentre as referidas competências, as 4 que se associam, ainda que indiretamente, à Fonética e à Fonologia:

\footnotetext{
1. Reconhecer a língua como meio de construção de identidades de seus usuários e da comunidade a que pertencem.

2. Compreender a língua como fenômeno cultural, histórico, social, variável, heterogêneo e sensível aos contextos de uso.

3. Demonstrar atitude respeitosa diante das variedades linguísticas, rejeitando preconceitos linguísticos.

5. Empregar, nas interações sociais, a variedade e o estilo de linguagem adequado à situação comunicativa, ao interlocutor e ao gênero textual.
}

Quadro 1. Competências Específicas de Língua Portuguesa para o Ensino Fundamental (Fonte: BRASIL, 2017, p. 66) 
Para reconhecer a língua como "meio de construção de identidades dos seus usuários" (competência 1) é necessário, dentre outros saberes, compreender que ela varia (competência 2) e que tal variação é especialmente evidente no nível dos sons. Além disso, a percepção da variação como fenômeno constitutivo das línguas, resultante da heterogeneidade dos grupos sociais, terá como consequência, dentre outros fenômenos: 1) a rejeição aos preconceitos linguísticos (competência 3), especialmente aqueles relativos a processos fonológicos que se observam na fala de pessoas com baixo ou nenhum grau de escolaridade, como o rotocismo e a transposição, por exemplo e 2) o desenvolvimento da habilidade de adequar a pronúncia das palavras às diferentes situações de comunicação (competência 5).

Com pretensões meramente ilustrativas, vejamos, a partir de uma breve análise de uma atividade extraída de um livro didático de Língua Portuguesa, como tais competências podem ser desenvolvidas. A imagem abaixo foi extraída da obra Português: Linguagens (CEREJA \& MAGALHÃES 2015). O nosso objetivo é mostrar que, ao completo desenvolvimento das competências constantes do quadro 1, o professor que decidir trabalhar com esse texto (ou com tantos outros semelhantes que se fazem recorrentemente presentes nos livros didáticos de Língua Portuguesa), precisa recorrer a conceitos da Fonética e da Fonologia, sob pena de perder a oportunidade de abordar tal fenômeno linguístico em sua complexidade.

\section{A Ingua em foco}

\section{AS VARIEDADES LINGUÍSTICAS}

\section{CONSTRUINDO O CONCEITO}

Leia a tira abaixo, de Fernando Gonsales.
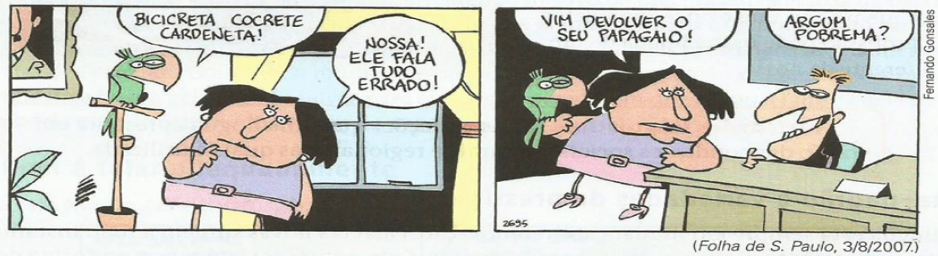

1. O humor da tira é construído a partir das diferenças de uso da língua portuguesa. No 1: quadrinho, o papagaio fala algumas palavras que causam estranhamento à mulher.

a) Que palavras causam estranhamento à mulher? Provavelmente todas as que o papagaio fala: "bicicreta", "cocrete", "cardeneta

b) Como provavelmente ela diria essas palavras? bicicleta, croquete, caderneta

2. Para que o leitor compreenda bem a tira, é necessário que ele tenha conhecimento sobre como os papagaios aprendem a falar. De que forma isso acontece? 0 papagaio aprende a falar imitando as pessoas com as quais ele convive.

3. No $2^{\circ}$ quadrinho, a mulher procura o comerciante para devolver o papagaio.

a) Qual é a provável relação entre o homem e o papagaio? Ele deve ser o dońa anterior do papagaio

b) A surpresa e a graça da tira estão na fala do comerciante. O que a fala dele revela?

prega a língua de uma forma diferente da norma-padrāo. Professor: o conceito de norma-padrão, vocé poderá explicar que a forma empregada pelo comerciante é diferente da que está registrada no dicionário.

Figura 1. Atividade extraída do livro didático de Língua Portuguesa.

Fonte: Português: Linguagens (CEREJA \& MAGALHÃES, 2015, p. 39) 
Nas falas do papagaio e do homem presentes na tirinha acima, as palavras "bicicleta", "croquete", "caderneta", "algum" e "problema" são pronunciadas como "bicicreta", "cocrete", "cardeneta", "argum" e "pobrema", respectivamente. Em "bicicreta", "argum" e "pobrema", temos três casos de rotacismo e, em "cocrete" e "cardeneta", acontece a transposição por metátase. Apesar de seremcomuns na fala de grupos sociais de baixo grau de escolaridade, tais fenômenos são apresentados de maneira caricata na atividade, a qual tem como pano de fundo uma visão estereotipada e, portanto, preconceituosa das diferentes normas linguísticas, em especial, daquelas praticadas por grupos sociais mais desfavorecidos. O texto evidencia uma variante linguística de cidadãos que, tendo tido o seu direito a uma educação de qualidade tolhido, são, historicamente, vítimas de vários tipos de preconceitos. E o preconceito linguístico é, talvez, o mais frequente. Essa abordagem, a nosso ver, em nada contribui com as reflexões que a escola precisa fazer acerca do complexo fenômeno das variedades linguísticas que caracterizam as línguas naturais. Ressalta-se, nesse contexto, o papel do professor de Língua Portuguesa na formação de alunos que, tendo os subsídios teóricos necessários, são capazes de se posicionar contra as mais diferentes manifestações do preconceito linguístico.

A conclusão semelhante chegou González (2015), em pesquisa em que analisou como livros de Língua Portuguesa aprovados pelo PNLD 2009 abordam a variação linguística. Segundo o autor, “[...] os livros mais adotados são os que trabalham a variação linguística de modo mais estereotipado e anedótico, contribuindo para a manutenção do discurso sobre o certo e o errado em língua." (GONZÁLEZ, 2015, p. 234)

O livro didático (LD) é o recurso mais presente nas salas de aula das escolas brasileiras e o professor que consegue usá-lo com autonomia é aquele que é capaz de olhar criticamente para tal material, de maneira a desenvolver uma prática autônoma, enquanto verdadeiro autor de suas aulas. A obra de onde foi extraído o texto acima vem sendo, há anos, a mais adotada pelas escolas públicas e privadas brasileiras. O gênero em pauta, texto de humor, e o seu conteúdo fazemse reiteradamente presentes nos LD de Língua Portuguesa das mais diferentes editoras, especialmente nas seções que abordam a temática da variação linguística.

Imaginemos, nesse contexto, um determinado professor que selecionou, na referida obra, tal texto para a sua aula sobre variação linguística. Como se afirmou acima, as falas das personagens giram em torno de um conteúdo muito específico da Fonologia, o qual precisa ser previsto pelo documento que orienta o currículo e, consequentemente, dominado pelo professor. Além disso, ao abordar o fenômeno da variação linguística, as obras didáticas comumente recorrem ao gênero piada, pelas razões supracitadas. Isso significa que o docente precisa ter os subsídios teóricos necessários acerca da Linguística, para não "embarcar" no discurso da estereotipação já referido e, pior, repassá-los para os discentes, numa prática pedagógica ingênua, submissa e acrítica. Entre tais subsídios teóricos, incluem-se a Fonética e a Fonologia, que, sendo dominadas pelo professor, precisam fazer-se presentes no currículo da Educação Básica como um todo, porque, assim como a Morfologia e a Sintaxe (para citar os dois níveis de análise linguística que, 
historicamente, possuem mais espaço no currículo), são áreas imprescindíveis ao desenvolvimento das competências constantes do Quadro 1 acima apresentado.

Nesse contexto, se, por um lado, o documento que regula o currículo nacional, ao prever a abordagem da Fonética e da Fonologia, não reconhece que a variação linguística que as constitui e, nesse sentido, deveria transversalizá-las, e se, por outro lado, o nosso professor hipotético não construiu tais conhecimentos em sua formação inicial e continuada, a rejeição ao preconceito linguístico e o respeito às variantes linguísticas que transversalizam as 5 competências constantes do quadro 1 muito dificilmente serão atingidos em sua plenitude.

Continuemos com a descrição da BNCC. Na seção seguinte, são esmiuçados as unidades temáticas, os objetos de conhecimento e as habilidades de Língua Portuguesa para o Ensino Fundamental Anos Iniciais e Finais. Nesta pesquisa, conforme anteriormente afirmado, objetivamos analisar a dimensão linguística do tratamento dado à Fonética e à Fonologia no Ensino Fundamental Anos Iniciais. Para tanto, foram contemplados pela análise apenas os segmentos do texto que abordam tais áreas e os quadros apresentados mais adiante são recortes dos que originalmente encontram-se na BNCC.

Ao determinar os objetos de conhecimento dos eixos de ensino de Língua Portuguesa para o Ensino Fundamental Anos Iniciais, o documento prevê: para a Oralidade, o aprofundamento dos conhecimentos construídos na Educação Infantil; para a Leitura e a Escrita, a ampliação do letramento; para a Educação Literária, a formação para a apreciação de textos literários orais e escritos; para os Conhecimentos Linguísticos e Gramaticais, a sistematização da alfabetização, a apreciação das regularidades linguísticas e a "[...] aprendizagem de regras e processos gramaticais básicos" (BRASIL, 2017, p. 67).

Os objetos de conhecimento do eixo dos Conhecimentos Linguísticos e Gramaticais acima referidos são aqueles que mais se fazem presentes na seção seguinte, intitulada "Considerações sobre o processo de alfabetização", em comparação com o que se prevê para os demais eixos. Nesse contexto, dos 10 tópicos que estruturam a seção em pauta, 5 mobilizam conhecimentos da Fonética e da Fonologia (conforme Quadro 2 a seguir). 
4. Tanto a fala quanto a escrita são produzidas em sequência linear, isto é, "som" depois de "som", ou letra depois de letra, palavra depois de palavra, frase depois de frase, e assim por diante. Um dos pontos fundamentais do início da alfabetização é compreender que essa linearidade acontece de maneira diferente na fala e na escrita.

5. A importância da aprendizagem do alfabeto na fase inicial da alfabetização está, sobretudo, na necessidade de o aluno saber identificar e nomear as letras. Além disso, um conhecimento básico é a regra geral de que o nome de cada letra tem relação com pelo menos um dos "sons" da fala [...]. Portanto, é fundamental que o aluno compreenda que as letras são unidades estáveis do alfabeto, que representam na escrita os "sons" vocálicos ou consonantais constitutivos das palavras faladas.

7. Uma das implicações do princípio de identidade funcional das letras para o processo de alfabetização é que o aluno precisa aprender que não pode escrever qualquer letra em qualquer posição na palavra, porque as letras representam fonemas, os quais aparecem em posições determinadas nas palavras.

8. Apropriar-se do sistema de escrita depende, fundamentalmente, de compreender um princípio básico que o rege, a saber: os fonemas, unidades de "som", são representados por grafemas na escrita. Grafemas são letras ou grupos de letras, entidades visíveis e isoláveis. Os fonemas são as entidades elementares da estrutura fonológica da língua, que se manifestam nas unidade sonoras mínimas da fala.

9. Um conhecimento fundamental que os alunos precisam adquirir no seu processo de alfabetização diz respeito à natureza da relação entre a escrita e a cadeia sonora das palavras que eles tentam escrever ou ler. [...] Isso significa compreender a natureza alfabética do sistema de escrita e se manifesta quando o aluno começa a tentar ler e escrever de acordo com o princípio alfabético (uma "letra", um "som").

10. A aprendizagem das regras ortográficas é parte indissociável do processo de alfabetização (p. 69)

Quadro 2. Considerações sobre o processo de alfabetização (Fonte: Brasil, 2017, p. 67-69)

O princípio que rege tais orientações é de que, assim como o letramento é imprescindível à alfabetização (e, consequentemente, à apropriação do aspecto grafofonêmico da língua), a alfabetização é indispénsável ao letramento.

Daí porque, pelo menos nesse nível do ensino ${ }^{11}$, dá-se um papel de destaque aos saberes relacionados à Fonética e à Fonologia no delineamento do texto. No item 4 , o documento prevê que haja a reflexão acerca das especificidades da fala e da escrita, no que tange à sua linearidade sequencial. Nos itens $5,6,7,8$ e 9, determina-se a efetivação do trabalho com as especificidades do sistema de escrita alfabética, em que grafemas representam fonemas. Por fim, em 10, chamase a atenção para a imprescindibilidade, para o processo de alfabetização, da aprendizagem das regras ortográficas.

No quadro abaixo, transcrevemos as unidades temáticas, os objetos do conhecimento $\mathrm{e}$ as habilidades delineados pelo documento em pauta para o Ensino Fundamental Anos Iniciais. Considerando os objetivos desta investigação, selecionamos apenas os dados que guardam relação com as áreas em estudo. Para tanto, contemplamos na análise saberes diretamente oriundos da Fonética e da Fonologia, como, por exemplo, as características do sistema alfabético de escrita, a consciência fonológica e a grafofonêmica. Além disso, foram também examinados todos os segmentos do texto em pauta que abordam a variação linguística. Obsevese o quadro abaixo.

${ }^{11}$ Dados de nossa pesquisa de pós-doutoramento que se encontra em curso mostram que os conteúdos da Fonética e da Fonologia não são previstos pela BNCC para nenhum ano do Ensino Fundamental Anos Finais. 


\begin{tabular}{|c|c|c|}
\hline \multicolumn{3}{|c|}{$1^{\circ} \mathrm{ANO}$} \\
\hline $\begin{array}{l}\text { UNIDADES } \\
\text { TEMÁTICAS }\end{array}$ & $\begin{array}{c}\text { OBJETOS DE } \\
\text { CONHECIMENTO }\end{array}$ & HABILIDADES \\
\hline \multicolumn{3}{|c|}{ EIXO ESCRITA - Prática de escrita de palavras e frases e de pequenos textos } \\
\hline $\begin{array}{l}\text { Apropriação do sistema } \\
\text { alfabético de escrita }\end{array}$ & Escrita de palavras e frases & $\begin{array}{l}(\mathrm{EF} 01 \mathrm{LP} 16)^{12} \text { Escrever, } \\
\text { espontaneamente ou por ditado, } \\
\text { palavras e frases de forma } \\
\text { alfabética - usando letras/ } \\
\text { grafemas que representem } \\
\text { fonemas. }\end{array}$ \\
\hline \multicolumn{3}{|c|}{$\begin{array}{l}\text { EIXO CONHECIMENTOS LINGUÍSTICOS E GRAMATICAIS - Compreensão e apropriação } \\
\text { do sistema alfabético de escrita, reflexão sobre convenções gráficas da escrita e ampliação do } \\
\text { léxico (vocabulário) }\end{array}$} \\
\hline \multirow[t]{3}{*}{$\begin{array}{l}\text { Apropriação do sistema } \\
\text { alfabético de escrita }\end{array}$} & $\begin{array}{l}\text { Compreensão do sistema } \\
\text { alfabético de escrita }\end{array}$ & $\begin{array}{c}\text { (EF01LP24) Reconhecer o } \\
\text { sistema de escrita alfabética } \\
\text { como representação dos sons } \\
\text { da fala. }\end{array}$ \\
\hline & Consciência fonológica & $\begin{array}{c}\text { (EF01LP27)Segmentar } \\
\text { oralmente palavras em sílabas. } \\
\text { (EF01LP28) Comparar palavras } \\
\text { identificando semelhanças e } \\
\text { diferenças entre sons de sílabas } \\
\text { iniciais, mediais e finais. }\end{array}$ \\
\hline & Conhecimento do alfabeto & $\begin{array}{c}\text { (EF01LP29) Identificar } \\
\text { fonemas e sua representação por } \\
\text { letras, comparando unidades } \\
\text { sonoras (palavras) com } \\
\text { significados próprios, mas que } \\
\text { se diferenciam por apenas um } \\
\text { fonema/letra (como fava/vaca, } \\
\text { mola/sola, cola/bola, mapa/ } \\
\text { mala) } \\
\text { (EF01LP30) Completar palavras } \\
\text { com fonema/letra inicial ou } \\
\text { medial, com base na esculta da } \\
\text { palavra ou em desenho que a } \\
\text { represente. } \\
\text { (EF01LP31) Reconhecer que } \\
\text { alterações na ordem escrita } \\
\text { dos grafemas provocam } \\
\text { alterações na composição e no } \\
\text { significado da palavra, fazendo } \\
\text { corresponder grafemas e } \\
\text { fonemas }\end{array}$ \\
\hline
\end{tabular}

${ }^{12}$ As habilidades constantes do documento são identificadas por códigos, que fazem referência ao nível de ensino, ao ano de escolaridade e à numeração de cada habilidade. No caso em pauta, temos: Ensino Fundamental, primeiro ano, lingua portuguesa, dezesseis (EF01LP16). 


\begin{tabular}{|c|c|c|}
\hline \multicolumn{3}{|c|}{$2^{\circ}$ ANO } \\
\hline $\begin{array}{l}\text { UNIDADES } \\
\text { TEMÁTICAS }\end{array}$ & $\begin{array}{l}\text { OBJETOS DE } \\
\text { CONHECIMENTO }\end{array}$ & HABILIDADES \\
\hline \multicolumn{3}{|c|}{$\begin{array}{c}\text { EIXO ESCRITA - Prática de produção de textos verbais, verbo-visuais e multimodais de } \\
\text { versos gêneros textuais. }\end{array}$} \\
\hline $\begin{array}{l}\text { Estratégias durante a } \\
\text { produção do texto }\end{array}$ & $\begin{array}{l}\text { Procedimentos linguístico- } \\
\text { gramaticais e ortográficos }\end{array}$ & $\begin{array}{l}\text { (EF02LP25) Utilizar, ao } \\
\text { produzir o texto, grafia correta } \\
\text { de palavras conhecidas ou } \\
\text { com estruturas silábicas já } \\
\text { dominadas, letras maiúsculas } \\
\text { em início de frases e em } \\
\text { substantivos próprios, } \\
\text { segmentação entre as } \\
\text { palavras, ponto final, ponto } \\
\text { de interrogação e ponto de } \\
\text { exclamação. }\end{array}$ \\
\hline \multicolumn{3}{|c|}{$\begin{array}{l}\text { EIXO CONHECIMENTOS LINGUÍSTICOS E GRAMATICAIS - Consolidação da } \\
\text { apropriação do sistema alfabético de escrita, reconhecendo a escrita de palavras com estruturas } \\
\text { silábicas menos complexas e amplição do léxico (vocabulário) }\end{array}$} \\
\hline \multirow[t]{2}{*}{$\begin{array}{l}\text { Apropriação do sistema } \\
\text { alfabético de escrita }\end{array}$} & Consciência grafofonêmica & $\begin{array}{c}\text { (EF02LP29) Ler e } \\
\text { escrever palavras com } \\
\text { correspondências regulares } \\
\text { diretas entre letras e } \\
\text { fonemas (f, v, t, d, p, b) e } \\
\text { correspondências regulares } \\
\text { contextuais (c e g e e e o, em } \\
\text { posição átona em final de } \\
\text { palavra) }\end{array}$ \\
\hline & Consciência silábica & $\begin{array}{l}\text { (EF02LP30) Segmentar } \\
\text { palavras em sílbas e remover } \\
\text { e substituir sílabas iniciais, } \\
\text { mediais ou finais para criar } \\
\text { novas palavras. }\end{array}$ \\
\hline \multirow[t]{2}{*}{ Ortografia } & Estruturas silábicas & $\begin{array}{c}\text { (EF02LP33) Ler e escrever } \\
\text { corretamente palavras com } \\
\text { sílabas CV, V, CVC, CCV, } \\
\text { identificando que existem } \\
\text { vogais em todas as sílabas. } \\
\text { (EF02LP34) Ler e escrever } \\
\text { corretamente palavras com } \\
\text { marcas de nasalidade (til, } \\
\text { m, n). }\end{array}$ \\
\hline & & $\begin{array}{l}\text { (EF02LP35) Memorizar a } \\
\text { grafia de palavras frequentes } \\
\text { no ambiente escolar e nos } \\
\text { textos lidos, independemente } \\
\text { da estrutura silábica e de } \\
\text { correspondências irregulares } \\
\text { grafemas-fonemas. }\end{array}$ \\
\hline
\end{tabular}




\begin{tabular}{|c|c|c|}
\hline \multicolumn{3}{|c|}{$3^{\circ}$ ANO } \\
\hline \multicolumn{3}{|c|}{ Habilidades comuns do $3^{\circ}$ ao $5^{\circ}$ ano } \\
\hline Variação linguística & Processos de variação linguística & $\begin{array}{l}\text { (EF35LP02) })^{13} \text { Identificar } \\
\text { fatores determinantes de } \\
\text { registro linguístico (formal, } \\
\text { informal), como: contexto, } \\
\text { ambiente, tema, estado } \\
\text { emocional do falante, grau } \\
\text { de intimidade entre os } \\
\text { falantes. } \\
\text { (EF35LP03) Ouvir } \\
\text { gravações, canções, textos } \\
\text { falados em diferentes } \\
\text { variedades linguísticas, } \\
\text { identificando características } \\
\text { regionais, urbanas e rurais } \\
\text { da fala. } \\
\text { (EF35LP04) Respeitar a } \\
\text { variação linguística como } \\
\text { característica de uso da } \\
\text { língua por diferentes grupos } \\
\text { regionais ou diferentes } \\
\text { camadas sociais, rejeitando } \\
\text { preconceitos linguísticos. }\end{array}$ \\
\hline \multicolumn{3}{|c|}{$\begin{array}{c}\text { Eixo Conhecimentos Linguísticos e Gramaticais - Práticas de análise linguística e gramatical } \\
\text { (como estratégia para o desenvolvimento produtivo das práticas de oralidade, leitura e escrita). } \\
\text { Apropriação do sistema alfabético de escrita e reflexão sobre os usos do léxico e de regularidades } \\
\text { no funcionamento da língua falada e escrita. }\end{array}$} \\
\hline $\begin{array}{l}\text { Apropriação do sistema } \\
\text { alfabético de escrita }\end{array}$ & Consciência grafofonêmica & \begin{tabular}{|c} 
(EF03LP23) Ler e \\
escrever palavras com \\
correspondências regulares \\
contextuais entre grafemas \\
e fonemas c/qu; g/gu; r/ \\
$\mathbf{r r}$; s/ss; $\mathbf{o}$ e não $\mathbf{u}, \mathbf{e}$ e não i \\
em sílaba átona em final de \\
palavra, e com marcas de \\
nasalidade (til, $\mathbf{m}, \mathbf{n})$ e com \\
dígrafos $(\mathbf{l}, \mathbf{n h}, \mathbf{c h})$
\end{tabular} \\
\hline Ortografia & Uso do dicionário & $\begin{array}{l}\text { EF03LP24) Recorrer ao } \\
\text { dicionário para esclarecer } \\
\text { dúvida sobre a escrita de } \\
\text { palavras, especialmente } \\
\text { no caso de palavras } \\
\text { com relações irregulares } \\
\text { grafema-fonema. } \\
\text { (EF03LP25) Ler e escrever } \\
\text { corretamente palavras } \\
\text { com sílabas } \mathbf{C V}, \mathbf{V}, \mathbf{C V C}, \\
\text { CCV, VC, VV, CVV, } \\
\text { identificando que existem } \\
\text { vogais em todas as sílabas }\end{array}$ \\
\hline
\end{tabular}

${ }^{13}$ Ensino Fundamental do $3^{\circ}$ ao $5^{\circ}$ ano, Língua Portuguesa, Competência 01. 


\begin{tabular}{|c|c|c|}
\hline Ortografia & $\begin{array}{c}\text { Estruturas silábicas } \\
\text { Acentuação }\end{array}$ & $\begin{array}{c}\text { (EF03LP26) Identificar } \\
\text { o número de sílabas de } \\
\text { palavras, classificando- } \\
\text { as em monossílabas, } \\
\text { dissílabas, trissílabas e } \\
\text { polissílabas. } \\
\text { (EF03LP27) Identificar a } \\
\text { sílaba tônica em palavras, } \\
\text { classificando-as em } \\
\text { oxítonas, pararoxítonas e } \\
\text { proparoxítonas. } \\
\text { (EF03LP28) Usar } \\
\text { acento grave (agudo } \\
\text { ou circunflexo) em } \\
\text { monossílabos terminados } \\
\text { em a, e e o e em palavras } \\
\text { oxítonas terminadas em a, } \\
\text { e e o seguidas ou não de s. }\end{array}$ \\
\hline \multicolumn{3}{|r|}{. } \\
\hline \multicolumn{3}{|c|}{$\begin{array}{l}\text { Eixo Conhecimentos Linguísticos e Gramaticais - Práticas de análise linguística e } \\
\text { gramatical (como estratégia para o desenvolvimento produtivo das práticas de oralidade, leitura } \\
\text { e escrita). Apropriação do sistema alfabético de escrita e reflexão sobre os usos do léxico e de } \\
\text { regularidades no funcionamento da língua falada e escrita }\end{array}$} \\
\hline Ortografia & Consciência grafofonêmica & $\begin{array}{c}\text { (EF04LP23) Grafar } \\
\text { palavras utilizando regras } \\
\text { de correspondência } \\
\text { fonema-grafema } \\
\text { regulares e contextuais. } \\
\text { (EF04LP24) Ler e } \\
\text { escrever, corretamente, } \\
\text { palavras com sílabas } \\
\text { V e CVV no casos em } \\
\text { que a combinação VV } \\
\text { (ditongo) é reduzida na } \\
\text { língua oral (ai, ei, ou). }\end{array}$ \\
\hline & \multirow{2}{*}{ Acentuação } & $\begin{array}{l}\text { (EF04LP25) Memorizar } \\
\text { a grafia de palavras de } \\
\text { uso frequente nas quais a } \\
\text { relação grafema-fonema } \\
\text { são irregulares e com h } \\
\text { inicial que não representa } \\
\text { fonema. }\end{array}$ \\
\hline & & $\begin{array}{l}\text { (EF04LP26) Usar } \\
\text { acento gráfico (agudo } \\
\text { ou circunflexo) em } \\
\text { paroxítonas terminadas } \\
\text { em - i(s), -1, -r, -ão(s). }\end{array}$ \\
\hline
\end{tabular}




\begin{tabular}{|c|c|c|}
\hline \multicolumn{3}{|c|}{$5^{\circ}$ Ano } \\
\hline \multicolumn{3}{|c|}{$\begin{array}{c}\text { Eixo Oralidade: Práticas de compreensão e produção de textos orais em diferentes contextos } \\
\text { discursivos }\end{array}$} \\
\hline Funcionamento do discurso oral & Característica da fala & $\begin{array}{l}\text { (EF05LP04) Identificar } \\
\text { aspectos lexicais, } \\
\text { fonológicos, prosódicos, } \\
\text { morfossintáticos e } \\
\text { semânticos específicos } \\
\text { do discurso oral } \\
\text { (hesitações, repetições, } \\
\text { digressões, ênfases, } \\
\text { correções, marcadores } \\
\text { conversacionais, pausas } \\
\text { etc.). }\end{array}$ \\
\hline \multicolumn{3}{|c|}{$\begin{array}{l}\text { Eixo Conhecimentos Linguísticos e Gramaticais - Práticas de análise linguística e gramatical } \\
\text { (como estratégia para o desenvolvimento produtivo das práticas de oralidade, leitura e escrita). } \\
\text { Reflexão sobre os usos do léxico e de regularidades no funcionamento da língua falada e escrita. }\end{array}$} \\
\hline Ortografia & Consciência grafofonêmica & $\begin{array}{l}\text { (EF05LP27) Grafar } \\
\text { palavras utilizando regras } \\
\text { de correspondência } \\
\text { fonema-grafema } \\
\text { regulares e contextuais e } \\
\text { palavras de uso frequente } \\
\text { com correspondências }\end{array}$ \\
\hline & Acentuação & $\begin{array}{c}\text { 1rregulares. } \\
\text { (EF05LP28) Acentuar } \\
\text { corretamente palavras } \\
\text { oxítonas, paroxítonas e } \\
\text { proparoxítonas. }\end{array}$ \\
\hline
\end{tabular}

Quadro 2. Unidades temáticas, objetos do conhecimento e habilidades relacionados à Fonética e à Fonologia e previstos para o Ensino Fundamental Anos Iniciais pela BNCC (Fonte: Brasil, 2017)

Morais (2012), pesquisador que possui larga experiência com investigações voltadas ao processo de apropriação do sistema de escrita alfabética durante os Anos Iniciais do Ensino Fundamental, lista quatro habilidades de consciência fonológica que considera importantes à alfabetização de um aluno. São elas: perceber o número de sílaba das palavras, de maneira a distinguir as maiores das menores; atentar para os sons vocálicos constantes de diferentes sílabas de uma mesma palavra; identificar vocábulos que se iniciam com o mesmo fonema; notar que os segmentos sonoros de uma mesma palavra são parecidos.

Naturalmente, o desenvolvimento de tais competências dá-se de forma gradual e, segundo o autor, espera-se que, no $1^{\circ}$ ano, o estudante conheça o princípio da relação letra-som que rege o sistema de escrita alfabética. Observamos que as unidades temáticas, os objetos do conhecimento e suas respectivas habilidades delineados pela BNCC para o supracidado ano estão em consonância com o que defende Morais (op.cit), pois o referido documento determina, para o eixo Conhecimentos Linguísticos e Gramaticais, o desenvolvimento das habilidades de compreensão e de apropriação do sistema alfabético de escrita, bem como a reflexão sobre as convenções gráficas da escrita. Saberes relativos à Fonética e à Fonologia são previstos também para o eixo da Escrita. 
Nos anos seguintes, observa-se uma progressão de nível de complexidade de tais habilidades: no $2^{\circ}$ ano, prevê-se a consolidação da apropriação do sistema alfabético de escrita realizada no ano anterior, o que também está em sintonia com o que defende Morais (op. cit, p. 127), quando afirma que "[...] o segundo ano deverá ser dedicado à consolidação das convenções grafema-fonema, de modo a permitir que as crianças manejem com segurança aquelas correspondências grafofonêmicas."

O autor defende também que, ao concluírem o $3^{\circ}$ ano, as crianças estejam mais seguras quanto à norma ortográfica, o que se coaduna com o que propõe $\mathrm{o}$ documento em análise, quando determina, para o referido ano: o domínio (quanto à leitura e à escrita) da grafia de palavras que possuem (ou não) correspondências regulares contextuais entre grafemas e fonemas (EF03LP23); a leitura e a escrita adequadas de vocábulos com sílabas simples e complexas (EF03LP25); a classificação de palavras quanto ao número de sílabas (EF03LP26) e quanto à tonicidade (EF03LP27) e o uso dos acentos agudo e cincunflexo em contextos específicos (EF03LP28).

Entre o $3^{\circ}$ e o $5^{\circ}$ ano, parte-se para as práticas de análise linguística e gramatical e para a reflexão acerca de regularidades inerentes à fala e à escrita. É nessa fase que se determinam habilidades comuns relativas à variação linguística, como se pode observar em EF35LP02, EF35LP03 e EF35LP04, no Quadro 2. Chamounos a atenção o fato de a variação linguística, em praticamente todo o texto, não aparecer relacionada aos níveis de análise linguística, dado que indica que ela não é considerada como um princípio constitutivo da língua (e, portanto, transversal a todos os níveis de análise linguística). Ela é tratada como um conteúdo que, por sua vez, relaciona-se, genericamente, a habilidades que abordam a variação diafásica (cfe EF35LP02), a diatópica (cfe EF35LP03) e a diastrática (EF35LP04). Tal fato contribui para a perpetuação de uma visão caricata da língua, por meio da exploração de estereótipos como aqueles a que nos referimos anteriormente.

Aúnica exceção a esse problema pode ser observada na habilidade EF04LP24, traçada para o quarto ano: "Ler e escrever, corretamente, palavras com sílabas V e CVV nos casos em que a combinação VV (ditongo) é reduzida na língua oral (ai, ei, ou)". A redução de ditongos é um fenômeno relevante, observável na fala coloquial de brasileiros ${ }^{14}$ dos mais diferentes níveis de escolaridade e já foi objeto de estudo de vários fonólogos. Ainda que ele possa acontecer, segundo Silva (2007), tanto nos ditogos crescentes - como em árduo /['ahdv] e vácuo/ ['vakv] - como nos decrescentes - como em peixe/['pe $\mathrm{j}]$ e caixa/['kaj $\left.\int \partial\right]$-, a BNCC contempla apenas esse útimo tipo, talvez porque esse fenômeno não seja consensual na literatura, havendo linguistas de peso, como o memorável Mattoso Câmara Júnior, que, no caso do Português do Brasil, reconhece a existência de 11 ditongos decrescentes e apenas 1 crescente:

${ }^{14}$ Bortoni-Ricardo (2011) afirma que a redução de ditongos crescentes é um processo que também se verifica no português não padrão europeu. 
[...] o ditongo, inegável em certas áreas como o Rio de Janeiro, não é um traço fonêmico geral do português e falta em outras áreas, como Lisboa, em Portugal, e o Rio Grande do Sul, no Brasil. É um aspecto precário da língua portuguesa [...]. Aceitando-o em português, mas só quando um dos elementos vocálicos é tônico [...], podemos enumerar 11 ditongos descrescentes e um, muito restrito, crescente. (CÂMARA JÚNIOR, 2011, p. 55)

Ao abordar a variação linguística como um conteúdo (ou unidade temática, na terminologia adotada pela BNCC), o documento perde uma excelente ocasião de oportunizar ao aluno, já nos anos iniciais de sua escolaridade, a introdução a uma compreensão de língua pautada no seu aspecto sociointerativo.

Como se afirmou anteriormente, o objetivo da presente pequisa foi analisar o espaço ocupado pela Fonética e pela Fonologia Base Nacional Comum Curricular (BRASIL, 2017), especificamente no Ensino Fundamental Anos Iniciais. A análise evidenciou que, apesar de tais áreas serem devidamente contempladas pelo referido documento, elas são dissociadas da variação linguística, aspecto que, sendo constitutivo das línguas, precisa transversalizar todos os níveis de análise linguística.

\section{CONSIDERAÇÕES FINAIS}

Os dados indicaram que, no documento em análise, a Fonética e a Fonologia têm papel de destaque no Ensino Fundamental Anos Iniciais, fazendo-se presentes durante todo o percurso de apropriação e de sedimentação do princípio de escrita alfabética. Entretanto, apesar de se embasar no sociointeracionismo discursivo para apresentar a sua compreensão de língua e de linguagem, a BNCC, ao apresentar as unidades temáticas, os objetos do conhecimento e as habilidades relativas à língua portuguesa, distancia-se de tal perpectiva, ao tratar a variação linguística como um conteúdo (um objeto do conhecimento) e não como um princípio que transversaliza os níveis de análise linguística, o que contribui com o fortalecimento da visão genérica e estereotipada do fenômeno.

\section{REFERÊNCIAS}

BORTONI-RICARDO, Stella Maris. Do campo para a cidade: um estudo sociolinguístico de migração e de redes sociais. São Paulo: Parábola, 2011.

BRASIL. Ministério da Educação. Base Nacional Comum Curricular. Brasília: MEC, 2017. Disponível em: http://basenacionalcomum.mec.gov.br/images/BNCC_publicacao.pdf. Acesso em: $04 / 04 / 2018$

BRASIL. Plano Nacional de Educação - PNE/Ministério da Educação. Brasília, DF: INEP, 2014.

CAGLIARI, Luiz Carlos. Alfabetização e Linguística. 11.ed. São Paulo: Scipione, 2009.

CÂMARA JÚNIOR, Mattoso. Estrutura da lingua portuguesa. 43.ed. Petrópolis: Vozes, 2011. 
CEREJA, Willian e MAGALHÃES, Tereza Cochar. Português: linguagens . $6^{\circ}$ ano. São Paulo: Atual, 2015.

GONZÁLEZ, César Augusto. Variação inguística em livros de portugues para o EM. In: ZILLES, Ana Maria Stahl e FARACO, Carlos Alberto. Pedagogia da Variação Linguística: língua, diversidade e ensino. São Paulo: Parábola Editorial, 2015.

MORAIS, Artur Gomes de. Ortografia: Ensinar e Aprender. São Paulo: Ática, 2009.

MORAIS, Artur Gomes de. Sistema de Escrita Alfabética. São Paulo: Melhoramentos, 2012.

RODRIGUES, Siane Gois Cavalcanti. \& NASCIMENTO, Glácia Renata Pereira. Compreensão de professores de língua portuguesa acerca da natureza de fenômenos relacionados à fonética $\mathrm{e}$ à fonologia subjacentes à dificuldade de escrita de estudantes do ensino básico. In: Revista Letras e Letras, vol 32/4-julho/dezembro/2016). Universidade Federal de Uberlândia (MG). Disponível em http://www.seer.ufu.br/index.php/letraseletras. Acesso em 08/08/2017.

SAUSSURE, Ferninand de. Curso de Linguística Geral. São Paulo: Cultrix, 2006 [1916].

SILVA, Thaís Cristóafaro. Fonética e Fonologia do Português: roteiro de estudos e guia de exercícios. São Paulo: Contexto, 2007.

SIMÕES, Darcilia. Considerações sobre a fala e a escrita: fonologia em nova chave. São Paulo: Parábola Editorial, 2006.

VELOSO, João e RODRIGUES, Aleaxandra Soares. A presença da fonética e da fonologia no ensino do português (ensino básico e secundário): algumas considerações preliminares, in Duarte, I. M. et al., Anais do Encontro Comemorativo dos 25 anos do Centro de Linguística da Universidade do Porto, vol. 1, Porto, C.L.U.P., 2002, (p. 231-246). Disponível em: https://bibliotecadigital. ipb.pt/handle/10198/3314 Acesso em 20/08/2017. 